Canadian

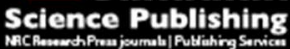

Canadian Geotechnical Journal Revue canadienne de géotechnique

\title{
Prediction of Water Content and Normalized Evaporation from Oil Sands Soft Tailings Surface Using Hyperspectral Observations
}

\begin{tabular}{|r|l|}
\hline Journal: & Canadian Geotechnical Journal \\
\hline Manuscript ID & cgj-2015-0416.R1 \\
\hline Manuscript Type: & Article \\
\hline Date Submitted by the Author: & 31 -Mar-2016 \\
\hline Complete List of Authors: & $\begin{array}{l}\text { Entezari, Iman; University of Alberta, Earth and Atmospheric Sciences } \\
\text { Rivard, Benoit; University of Alberta, Earth and Atmospheric Sciences } \\
\text { Lipsett, Michael; University of Alberta, Mechanical Engineering } \\
\text { Wilson, Ward; University of Alberta, Civil \& Environmental Engineering }\end{array}$ \\
\hline Keyword: & Oil Sands, Tailings, Hyperspectral data, Moisture content, Evaporation \\
\hline
\end{tabular}




\title{
Prediction of Water Content and Normalized Evaporation from Oil Sands Soft Tailings Surface Using Hyperspectral Observations
}

\author{
Iman Entezari $^{\mathrm{a}}$, Benoit Rivard ${ }^{\mathrm{a}^{*}}$, Michael G. Lipsett $^{\mathrm{b}}$, G. Ward Wilson ${ }^{\mathrm{c}}$ \\ ${ }^{\mathrm{a}}$ Department of Earth and Atmospheric Sciences, University of Alberta, \\ 1-26 Earth Sciences Building, Edmonton, Alberta, Canada T6G 2E3, \\ \{entezari, benoit.rivard\}@ualberta.ca \\ ${ }^{b}$ Department of Mechanical Engineering, University of Alberta, \\ 5-8J Mechanical Engineering Building, Edmonton, Alberta, Canada T6G 2G8, \\ mlipsett@ualberta.ca \\ ${ }^{c}$ Department of Civil and Environmental Engineering, University of Alberta, \\ 3-069 Markin/CNRL Natural Resources Engineering Facility, Edmonton, Alberta, \\ Canada T6G 2W2,ward.wilson@ualberta.ca
}

${ }^{*}$ Corresponding author. Tel.: 1-780-492-0349; fax: 1-780-492-2030.

E-mail: benoit.rivard@ualberta.ca

March 31, 2016 


\begin{abstract}
The paper addresses the challenge of measuring water content and evaporative fluxes from oil sands soft tailings surfaces using hyperspectral observations. Hyperspectral timeseries laboratory observations were collected from four different Mature Fine Tailings (MFT) samples displaying variations in swelling potential and bitumen concentration. The samples were allowed to evaporate from an initial state of water saturation to an air-dried state. From these data, several spectral features were evaluated to predict water content and normalized evaporation rate from the optically sensed portion of the tailings surface $(<\mathrm{a}$ few $100 \mu \mathrm{m})$. For the samples tested, the best estimate of moisture content was achieved using the Normalized Soil Moisture Index (NSMI) index $\left(\mathrm{R}^{2}=0.97\right)$. The absolute reflectance at $1920 \mathrm{~nm}$ was found to be the best spectral estimator of normalized evaporation $\left(\mathrm{R}^{2}=0.97\right)$ with the NSMI index also being of value $\left(\mathrm{R}^{2}=0.95\right)$. In both instances, the NSMI index may be of value for estimations attempted in the field. In the case of tailings management, the remote estimation of moisture content and evaporation could help to assess the drying process, to determine when the deposit has stopped drying at the surface as part of a decision when the next lift should be deposited. In future efforts, the models obtained from this laboratory investigation will be assessed for their applicability in field settings and validated using concurrent sampling.
\end{abstract}

Keywords: Oil sands, Tailings, Mature Fine Tailings, Hyperspectral data, Moisture content, Evaporation. 


\section{Introduction}

The oil sands of northern Alberta comprise the third largest proven reserves of petroleum in the world (Alberta Energy 2014). Oil sands are a natural unconsolidated mixture of sand, clays and other minerals, water, and bitumen, a viscous petroleum high in residuals and asphaltenes. Bitumen must be separated from the solids and water so that it can subsequently be upgraded and refined into petroleum products, primarily transportation fuels. Depending on the depth of the oil sand deposits, bitumen extraction is done either by in-situ or surface mining methods. Bitumen does not flow naturally through a deposit, due to its high viscosity at ambient temperatures. In-situ production entails extracting bitumen from underground deposits by injecting steam and solvents to reduce viscosity and allow flow within an artificially created reservoir. Surface mining is done for deposits with overburden of less than approximately 75 meters (National Energy Board 2004). In surface mining, the ore is conditioned with reagents in warm water and agitated to separate bitumen from the oil sand matrix and to aerate bitumen droplets. Aerated bitumen then floats to the top of a separation vessel. The bitumen-rich froth is then diluted with a solvent and put through additional separation steps to reduce the amount of water and fine solids in the bitumen. Nonaqueous bitumen extraction processes are in development; but they have not been commercially implemented. The water-based separation process requires about two barrels of water for each barrel of bitumen produced, resulting in large volumes of tailings, comprising mostly water with sand, silt, clay, and residual bitumen. When the tailings are discharged into the tailings pond, the coarse sand particles settle to the bottom quickly, forming a beach and trapping some fine solids in interstices. The remaining fine solids settle slowly. This mixture naturally densifies to about $30 \mathrm{wt} \%$ fines/fines-plus-water within a few years in a settling basin, forming Mature Fine Tailings (MFT) (MacKinnon 1989). Released water clarifies fairly quickly and is recycled in the extraction process. The MFT remains saturated for 
decades because of its very slow natural consolidation rate (Kasperski 1992; MacKinnon 1989), and so it has essentially no bearing strength (FTFC 1995).

One of the long-term goals in tailings management is to remove the water from solids so that a trafficable load-bearing surface can be produced (with an undrained shear strength significantly greater than $10 \mathrm{kPa}$ ) for terrestrial reclamation (BGC Engineering Inc. 2010). Water removal from saturated tailings is the process of densifying and consolidating tailings. The separation of water from MFT is thus an operational and environmental challenge of tailings management.

In the past few decades, several engineering techniques have been proposed and tested to accelerate water removal and increase the performance of the consolidation process of MFT. The composite tailings or consolidated tailings (CT) process combines gypsum as a coagulant with MFT mixed with tailings sand, which acts as a charge to accelerate densification (FTFC 1995; Boratynec 1998). Thickened tailings processes (TT) use flocculants to form agglomerates in MFT that will settle more quickly and in appropriate conditions to form dense (dewatered) deposits that develop sufficient shear strength to be covered with reclamation material (Scott et al. 2008). New processes use beaching of flocculated tailings in thin lifts to promote faster desiccation, or the process employs centrifugation of flocculated tailings to produce a dense paste deposit with sufficient bearing strength to support a load (Mikula et al. 2009).

Flocculating and drying of MFT has been tested by several oil sands operating companies (COSIA/OSTC 2012). The method typically employs the deposition of layers of in-line flocculated MFT into drying cells where the lifts are allowed to de-water to a solids content with negative pore pressure that - under the right conditions - yields a consolidated soil that meets the specified shear strength requirements. The duration of the drying time required depends on: i) the rate of evaporation associated with the climatic conditions for 
each day throughout the spring, summer and fall seasons, ii) precipitation, iii) the degree of drying and associated values of total suction at the surface of the MFT for each lift, iv) the thickness of the lift, and v) the soil property functions of the MFT (i.e. Soil-water characteristic curve and hydraulic conductivity functions). Optimization of the drying operation with respect to the key cycling parameters of lift thickness and drying time requires real-time quantification of the actual rate of evaporation at the surface of the tailings, which in turn depends on atmospheric forcing conditions as well as the water content and associated total suction at the surface of the MFT as the material progresses through each evaporation cycle.

The present work investigates the potential of using remote sensing methods to develop techniques for the estimation of water content and evaporative fluxes from the optically sensed portion of the tailings surface $(<\mathrm{a}$ few $100 \mu \mathrm{m})$. Hyperspectral time-series laboratory observations are collected from MFT samples that are allowed to evaporate from an initial state of water saturation to an air-dried state. From these data several spectral features are evaluated to predict water content and normalized evaporation rate. The ability to quickly measure the water content and evaporation flux of tailings surfaces from a standoff distance could allow for estimation of drying progress of treated tailings without physical sampling campaigns (which are laborious and expensive) (Lipsett et al. 2014). Simple surveying of the surface of a treated area may provide insights into the effectiveness of tailings processes that allow decisions on scheduling the deposition of new lifts, and when placement of reclamation material can be done.

\section{Background}

Potential evaporation (PE) can be defined as the maximum rate of evaporation from a pure water surface under a given climatic condition. The term was first introduced by 
Thornthwaite (1948) who developed a method to calculate PE based on mean monthly temperature. The rate of evaporation from a water surface can be simply computed using the well-known Dalton's equation (Gray 1970):

$$
E=f(u)\left(e_{s}-e_{a}\right)
$$

where $E$ is the rate of evaporation ( $\mathrm{mm} /$ day), $f(u)$ is transmission function which depends on the mixing characteristics of the air above the evaporating surface, $e_{s}$ is the saturation vapour pressure of water at the surface temperature $(\mathrm{kPa})$, and $e_{a}$ is the air vapour pressure in the atmosphere above the water surface $(\mathrm{kPa})$. According to Dalton's equation, evaporation can be described by Fick's Law as a function of the difference between the vapour pressure of the evaporating surface and that of the air above it. The application of Dalton's equation to calculate the evaporation in field settings can be challenging mainly because of difficulties in: i) determining the temperature of the evaporating surface and thus the saturation vapour pressure (Gray 1970), and ii) evaluating the transmission function, which needs to be established empirically (Gray 1970) or on the basis of rigorous aerodynamic profiles and eddy diffusion similarity theory (Wilson et al. 1997). Although Dalton's equation often remains indeterminate, it is the basis of the widely used Penman method (Penman 1948) in which the energy balance and the net radiation available to the evaporating water surface are used to resolve the difficulty associated in determining the surface temperature. Penman also presented a method based on measurement of the mean wind speed to determine the transmission function. The Penman method, however, assumes that water is always freely available to the surface and thus is applicable for the estimation of evaporation from a saturated soil surface. Accordingly, the actual evaporation (AE) from a soil surface is approximately equal to the potential evaporation from a free water surface as long as the soil 
is fully saturated (Penman 1948). However, as the surface begins to dry and becomes unsaturated, the Penman model becomes inaccurate in the estimation of actual evaporation due to soil suction forces.

Traditional models developed for the calculation of potential evaporation provide an overestimation of evaporation when applied to unsaturated soil surfaces, because the basic assumption in these models is that water is freely available to the surface (Morton 1985; Granger 1989a). Numerous efforts have been implemented to evaluate the actual evaporation (AE) from unsaturated soil surfaces. It has been shown that AE begins to decrease when the availability of water becomes limited and the soil is no longer saturated (Gray 1970; Morton 1975; Brutsaert 1982). Fig. 1(a) shows the typical relationship between normalized evaporation $(\mathrm{AE} / \mathrm{PE})$ defined as the ratio of actual evaporation to the potential evaporation and water availability for sand and clay soil surfaces, after Holmes (1961) and Gray (1970). $\mathrm{AE} / \mathrm{PE}$ equals unity for both sand and clay soils when the soil surface is saturated or the water content is high. The normalized evaporation starts to decline when water availability decreases. The behaviour of curves in Fig. 1(a) is not constant for different soils; and it depends on the water availability, soil texture, and drying rate (Wilson et al. 1997). Empirical models have been developed to estimate the evaporation from unsaturated soil surfaces (Hillel 1980; Yanful et al. 1993), because of the difficulty in determining the soil characteristics that control the evaporation from unsaturated soils.

Efforts have also been made to develop models on the basis of the soil variables that control evaporation from unsaturated soil surfaces (Barton 1979; Hammel et al. 1981; Granger 1989b; Wilson et al. 1994). Wilson et al. (1997) found that the decline in actual evaporation from unsaturated soil surfaces happens when the total suction exceeds the value of approximately $3000 \mathrm{kPa}$. As the total suction increases the evaporation decreases to reach zero. The relationship between total suction and AE/PE was found to be consistent for all the 
soil types and independent of water content, texture, and mineralogy, as illustrated in Fig. 1(b). According to Wilson et al. (1997), if the soil, water, and air temperature are approximately the same, then $\mathrm{AE} / \mathrm{PE}$ can be computed as:

$$
\frac{A E}{P E}=\left[\frac{\exp \left[\frac{\psi g W_{v}}{R T}\right]-h_{a}}{1-h_{a}}\right]
$$

where $\psi$ is total suction expressed as equivalent matric suction (head) and has a negative value $(\mathrm{m}), g$ is acceleration due to gravity $\left(\mathrm{m} / \mathrm{s}^{2}\right), W_{v}$ is the molecular weight of water $(0.018$ $\mathrm{kg} / \mathrm{mol}), R$ is the universal gas constant $(8.314 \mathrm{~J} /(\mathrm{mol} . \mathrm{K})), T$ is the soil temperature $(\mathrm{K})$, and $h_{a}$ is the relative humidity of the air. Although Eq. (2) provides a good mean to estimate $\mathrm{AE} / \mathrm{PE}$, measuring total suction and temperature of the soil surface is still required.

In general, to provide good estimates of evaporative fluxes, both climatic parameters and soil properties must be measured, which is a difficult task in field applications. Therefore, the objective of this paper is to evaluate the potentials of remote hyperspectral technology in estimation of normalized evaporation and moisture content in which there is no need to measure soil and climatic properties. The spectral models are developed by performing evaporation tests and collecting spectral time series in the laboratory. A range of tailings samples are examined to assess the robustness of spectral estimators against the tailings composition. 


\section{Materials and Methods}

\section{Sample suite}

A suite of 4 MFT samples was provided by a major oil sands operator in northern Alberta. The samples were characterized for Methylene Blue Index (MBI), bitumen content, solid content, and particle size distribution (PSD) (Table 1). MBI is an indicator of the swelling potential of the tailings and depends on the type and relative abundance of clay minerals and their total content in the sample. According to Da Silva et al. (2014), a typical MFT is predominantly comprised of approximately $40 \mathrm{wt} \%$ quartz, $30 \mathrm{wt} \%$ kaolinite, $10 \mathrm{wt} \%$ illite and contains traces of siderite, albite, microcline, greigite, pyrite, dolomite, calcite, tenorite, halite, rutile, and anatase. In addition, pore water of MFT contains nearly $12(\mathrm{mg} / \mathrm{L})$ $\mathrm{Ca}^{2+}$ and has a $\mathrm{pH}$ of approximately 8 , both of which play a significant role in the dispersion and flocculation of MFT (Da Silva et al. 2014). The samples were exposed to the evaporation tests to assess the sensitivity of the spectral measurements to the sample composition. Each sample was stirred to create a homogenous mixture before conducting the experiments in April 2014, as the samples had segregated after long-term storage in their polyethylene storage containers. Air-dried condition of the samples examined is shown in Fig. 2(a).

\section{Experimental approach}

The experimental approach was selected to derive a prediction of MFT moisture content and AE/PE from the optically sensed portion of the tailings surface $(<\mathrm{a}$ few $100 \mu \mathrm{m})$ using hyperspectral observations. The evaporation tests were conducted using the experimental setup developed by Wilson et al. (1997). Spectral time-series data were collected for MFT samples at variable moisture conditions to determine the spectral metrics of greatest sensitivity and to derive predictive models. Each evaporation test was performed using two identical circular evaporation pans (polystyrene petri dish), with $150 \mathrm{~mm}$ diameter, 
to measure $\mathrm{AE}$ and PE concurrently. One pan contained a thin layer of MFT to measure the actual evaporation rate $(\mathrm{AE})$ and the second contained water to measure the potential evaporation rate $(\mathrm{PE})$. Each container was put on a scale to continually monitor the mass change of the MFT sample and water, to determine the moisture content and actual and potential rates of evaporation.

Two identical $50 \mathrm{~W}$ quartz halogen lamps were used to illuminate each of the containers and thus to create an identical heat source over each container. Two thermocouples were embedded in the perimeter of each petri dish to monitor the temperature of tailings and water. Air temperature and relative humidity were also measured using a digital relative humidity and temperature sensor.

The evaporation experiments were started when tailing samples were initially saturated and continued until the samples were completely air dried. The mass and temperature of MFT and water, the temperature and relative humidity of air, and the spectra of MFT were simultaneously measured every 4 minutes, as drying took place. Each experimental trial took 2-2.5 hours. Fig. 2(b) shows the experimental setup used to conduct the evaporation tests.

The MFT samples were made as thin as possible due to two reasons: 1) to minimize the effect of water content below the evaporating surface as the total suction at the soil surface controls the evaporation characteristics of $\mathrm{AE} / \mathrm{PE}$, and 2) to minimize decoupling between spectral measurements and tailings bulk properties, as the reflectance is a surface phenomenon collected from a few hundred microns in depth. Extensive effort was exerted to create a thin layer of tailings with a uniform thickness. Approximately $20 \mathrm{~g}$ of tailings was poured onto the petri dish and then a plastic spoon was used to gently spread the materials over the entire pan and create a thin sample of uniform thickness. Thickness uniformity was 
assessed qualitatively by visual inspection. The tailings were not viscous and some spreading occurred naturally.

Tailings samples with known varying degree of swelling potential (determined with MBI) and residual bitumen were tested to assess the robustness of spectral estimators against the tailings composition. Spectral features, such as absolute reflectance and absorption depth, were derived from the collected spectral time series. Linear regression analysis was used to link the spectral features to the moisture content and the normalized evaporation. Coefficients of determination $\left(\mathrm{R}^{2}\right)$ were calculated to assess the accuracy of the spectral models. A summary of the evaporation tests is provided in Table 2.

\section{Collection of optical measurements}

Reflectance spectra of MFT surfaces were obtained using an ASD Fieldspec 3 Max spectrometer with a spectral range of $350-2500 \mathrm{~nm}$, and a nominal spectral resolution of 1 $\mathrm{nm}$. In this paper, however, focus was on the Short Wave Infra-Red (SWIR) region that extends from 1000 to $2500 \mathrm{~nm}$.

Illumination of the sample was provided by a $50 \mathrm{~W}$ lamp positioned at an incidence angle of approximately $20^{\circ}$. The radiance spectrum from the sample was collected with the ASD pointing at a normal viewing angle to the sample surface and sensing a sample footprint almost equal to the petri dish diameter $(150 \mathrm{~mm})$. A spectrum was acquired at each time interval of 4 minutes and was the result of averaging 25 measurements, a process that took less than 3 seconds. To obtain a reflectance spectrum, the sample radiance spectrum was normalized to that of a standard white reference panel measured at the beginning of the experiment. Example reflectance spectra of the wet and dry MFT1 sample are shown in Fig. 2(c). 


\section{Spectral metrics evaluated}

The reflectance spectra collected from the tailings samples during evaporation are affected by variations of the samples water content over time. Using the time series data (AE/PE, moisture content and reflectance spectra) different spectral metrics were compared in terms of their ability to estimate the water content and normalized evaporation of MFTs. The spectral features examined comprised absolute reflectance values, absorption depths, and the normalized soil moisture index (NSMI) (Haubrock et al. 2008). To determine appropriate wavelengths at which to examine absolute reflectance, a correlation analysis was performed between the absolute reflectance at all SWIR bands and water content and normalized evaporation, taking all the samples into account. The depth of absorption features attributable to water and centered at 1450 and $1925 \mathrm{~nm}$ was evaluated as a potential spectral metric for moisture content and evaporation estimation. For this purpose, the depth of the absorption band at $1450 \mathrm{~nm}$ and at $1925 \mathrm{~nm}$ were calculated using the continuum removed spectra between 1375 and $1550 \mathrm{~nm}$ and 1850 and $2150 \mathrm{~nm}$. Lastly this study examined the normalized soil moisture index (NSMI) suggested by Haubrock et al. (2008). NSMI is calculated as the normalized difference of the absolute reflectance at 1800 and $2119 \mathrm{~nm}$ wavelengths. This index has proved to be a good water content estimator for a range of natural soils.

\section{Calculation of moisture content and $A E / P E$}

The gravimetric water content $(\mathrm{GWC})$ at each time step of the experiments was calculated by measuring the weight of the sample and comparing it to the weight of the dried solids obtained at the end of the test. 


$$
G W C=\frac{W_{\text {sample }}-W_{\text {solids }}}{W_{\text {sample }}} .100
$$

where Wsample and Wsolids are the weight of the sample (water plus solids) and weight of dried solids, respectively. The normalized evaporation, AE/PE, was calculated using the changes in mass of the tailings and water measured at each time interval.

\section{Results}

\section{Behaviour of water content and AE/PE over time}

Figs. 3(a) and 3(b) show the moisture content and AE/PE with respect to time for all samples tested in this study. The offset between the behaviour of MFT1 and other samples is due to the lower initial water content of this sample.

The behaviour of curves shown in Fig. 3(b) is similar to those shown in Fig. 1(a) given by Holmes (1961), except that $\mathrm{AE} / \mathrm{PE}$ has been plotted as a function of time rather than water availability. According to Holmes (1961), when the soil is saturated or the water content is high, the $\mathrm{AE}$ is equal to $\mathrm{PE}$ and thus the normalized evaporation (i.e. $\mathrm{AE} / \mathrm{PE}$ ) equals unity for the clay and sand soils. For the samples tested in this study, however, the normalized evaporation is greater or less than unity as seen in Fig. 3(b). This deviation from unity is mainly attributed to decoupling between the water and soil temperature as the aerodynamic condition above the water and tailings containers was the same during each experiments. Knowing the temperature of the tailing and water, the potential evaporation can be corrected and thus the normalized evaporation. The potential evaporation is adjusted using the tailings temperature (i.e. the potential rate of evaporation is calculated at the tailings temperature using the Dalton's equation). Nevertheless, due to the bias existing between the actual tailings temperature and its temperature measured by the thermocouples, it was not 
possible to correct the normalized evaporation using the tailings temperature. This temperature discrepancy is due to embedding the thermocouple in the perimeter of the tailings container so that it is not seen by the spectrometer sensor. The tailings temperature measured with the thermocouple is thus not fully representative of the average temperature of the entire sample. Therefore, to correct the normalized evaporation for each curve, the average of the $\mathrm{AE} / \mathrm{PE}$ was calculated before the $\mathrm{AE} / \mathrm{PE}$ starts to decline from its constant behaviour and all the data values were divided by this average value. Fig. 3(c) shows the corrected normalized evaporation versus time. $\mathrm{AE} / \mathrm{PE}$ is approximately unity for all the samples at the start of the evaporation tests. These corrected normalized evaporation values were then used for further analysis.

\section{Relationship between AE/PE and water content}

The AE/PE versus gravimetric water content is shown in Fig. 3(d). All the curves show a similar behaviour and one comparable to that shown in Fig. 1(a) by Holmes (1961). When the water content is high, all the samples continue to evaporate at a near potential rate and then start to decline as the availability of water is decreased. The normalized evaporation reaches zero when each sample becomes air dried. For all samples examined in this study, the normalized evaporation declines at a water content of approximately $30 \mathrm{wt} \%$. This drop in evaporation at a water content of $30 \mathrm{wt} \%$ is in close agreement with the results obtained by Wilson et al. (1997) for Regina Clay samples. The slight variation in behaviour between the samples is attributed to the variations in the composition and thickness of the samples, as well as relative humidity of the air at the time of each experiment. 


\section{Relationship between spectral features and water content}

Absolute reflectance

The correlation coefficient between water content and absolute reflectance for each SWIR wavelength is shown in Fig. 4(a). In general, reflectance in the SWIR has a high negative correlation with water content. The highest correlation was observed at $1985 \mathrm{~nm}$. Plots of water content versus absolute reflectance at $1985 \mathrm{~nm}$ for all the samples are shown in Fig. 4(b). The behavior of the $1985 \mathrm{~nm}$ reflectance above approximately $30 \mathrm{wt} \%$ water content is significantly affected by specular reflection where water is present within the field of view. Below $30 \mathrm{wt} \%$ moisture content, the data define two groups formed by MFT samples $1 \& 3$ and samples $2 \& 4$. The separation between these groups appears to be mainly due to non-uniform drying patterns rather than the composition of the samples. The effects of specular reflection and non-uniform drying patterns on the reflectance spectra are expanded upon in the Discussion section. Although MFT samples $1 \& 3$ show almost the same behaviour below $30 \mathrm{wt} \%$, MFT3 shows a lower reflectance than MFT1 below $10 \mathrm{wt} \%$ water content because of its higher bitumen concentration. It can be concluded that when the sample is wet (above $10 \mathrm{wt} \%$ moisture content), the impact of bitumen on the reflectance is insignificant; but it lowers the reflectance when the sample surface dries (below $10 \mathrm{wt} \%$ water content). Also, it is observed that below approximately $5 \mathrm{wt} \%$ moisture content, the behavior of the reflectance at $1985 \mathrm{~nm}$ is nonlinear. This reflects the progressive loss of sensitivity of the spectral measurement to the dehydration process when the surface is dry. Deeper parts of the sample likely then loose moisture due to the progressive development of fractures. If one were to use the reflectance at $1985 \mathrm{~nm}$ for imagery acquired outdoors (e.g. tailings illuminated by sunlight), the presence of water vapor in the intervening atmosphere would severely impact the quality of the spectral measurements. Consequently, the reflectance at $2205 \mathrm{~nm}$ was also examined (Fig. 4(c)) as it is minimally impacted by 
atmospheric effects. As can be seen in Fig. 4(c), the behaviour of graphs is similar to the $1985 \mathrm{~nm}$ reflectance except for having a smaller range of variation ( 0.1 to 0.3 compared to 0.05 to 0.33 in case of $1985 \mathrm{~nm}$ reflectance). Because the variation of both the $1985 \mathrm{~nm}$ and $2205 \mathrm{~nm}$ reflectance above $30 \mathrm{wt} \%$ water content is affected by specular reflection from the water surface, the potential of these spectral features was evaluated only below $30 \mathrm{wt} \%$. To account for the nonlinear behavior of the reflectance at $1985 \mathrm{~nm}$ and $2205 \mathrm{~nm}$ below $5 \mathrm{wt} \%$ moisture content, second-order polynomials were employed to fit the data. $\mathrm{R}^{2}$ values of 0.95 and 0.94 were achieved for reflectance at $1985 \mathrm{~nm}$ and $2205 \mathrm{~nm}$, respectively. Although both these features are of value for the estimation of water content in the laboratory, only the reflectance of $2205 \mathrm{~nm}$ is of value for outdoor scenarios due to its robustness against atmospheric conditions.

\section{Absorption depth}

Figs. 4(d) and 4(e) show the changes in absorption depths at $1450 \mathrm{~nm}$ and $1925 \mathrm{~nm}$ with respect to water content for each sample, respectively. Both of these features appear to be sensitive to the changes in water content for the entire moisture regime, with a slight decline in sensitivity of $1450 \mathrm{~nm}$ depth below $8 \mathrm{wt} \%$ moisture content. The absorption depth at $1925 \mathrm{~nm}$, however, shows a higher range of variation than the $1450 \mathrm{~nm}$ band depth. The range of variation for the $1925 \mathrm{~nm}$ depth is roughly from 0 to 0.7 compared to 0 to 0.35 in case of $1450 \mathrm{~nm}$ depth. Similar to absolute reflectance at $1985 \mathrm{~nm}$, samples form two populations in $1925 \mathrm{~nm}$ absorption depth attributed to the non-uniform dehydration. The $1450 \mathrm{~nm}$ absorption depth, on the other hand, seems to be more robust against the pattern of dehydration (Fig. 4(d)). In general, both features are insensitive to the tailings composition including bitumen. $\mathrm{R}^{2}$ values of 0.96 and 0.95 were obtained by fitting a second-order polynomial considering the entire set of data points for $1450 \mathrm{~nm}$ and $1925 \mathrm{~nm}$ absorption 
features, respectively. Such a polynomial accounts for the changes in the data patterns as the sample goes from encompassing standing water to loosing standing water at a moisture content of approximately $40 \mathrm{wt} \%$. This pattern is observed for the band depth at $1450 \mathrm{~nm}$, $1925 \mathrm{~nm}$ and the NSMI results of the next section.

Although there is a strong correlation between the absorption bands at $1450 \mathrm{~nm}$ and $1925 \mathrm{~nm}$ and water content, both spectral regions would be of diminished value for the analysis of imagery acquired outdoors due to the strong absorption of sunlight by water vapor in the intervening atmosphere.

NSMI

The relationship between NSMI and water content for each tailings sample is shown in Fig. 4(f). The data shown in this figure suggest that NSMI shows a good level of robustness against tailings composition. Furthermore, it is sensitive to the variation in water content for the entire moisture regime. $\mathrm{R}^{2}$ of 0.97 was achieved by fitting a second-order polynomial to the data. This high $\mathrm{R}^{2}$ value and the fact that this index is not affected by the atmosphere make NSMI an appropriate water content estimator in field condition.

\section{Relationship between spectral features and $A E / P E$}

Since for all the tailings samples examined, the AE/PE was approximately unity above $30 \mathrm{wt} \%$ water content, the relationship between spectral features and $\mathrm{AE} / \mathrm{PE}$ was evaluated below this moisture level.

\section{Absolute reflectance}

A correlation analysis was performed between $\mathrm{AE} / \mathrm{PE}$ and the absolute reflectance at SWIR wavelengths, as shown in Fig. 5(a). Although reflectance in the SWIR generally has a 
high correlation with $\mathrm{AE} / \mathrm{PE}$, the highest correlation value was observed at $1920 \mathrm{~nm}$. Since $1920 \mathrm{~nm}$ is located at the centre of the water absorption band, absolute reflectance at 2205 nm was also examined. Figs. 5(b) and 5(c) show plots of AE/PE versus absolute reflectance at $1920 \mathrm{~nm}$ and $2205 \mathrm{~nm}$ for all the samples, respectively. Both features show a similar pattern with respect to $\mathrm{AE} / \mathrm{PE}$; the absolute reflectance increases with decreasing evaporation. The absolute reflectance at $2205 \mathrm{~nm}$, however, shows a less range of variation than the 1920 $\mathrm{nm}$. The range of variation for the $2205 \mathrm{~nm}$ reflectance is roughly from 0.15 to 0.29 compared to 0.1 to 0.32 in case of $1920 \mathrm{~nm}$. Both features show a good level of robustness against the tailings composition. However, it seems that absolute reflectance at $2205 \mathrm{~nm}$ is more affected by bitumen concentration. The sample MFT3 shows generally a lower reflectance at $2205 \mathrm{~nm}$ than the other samples, but this behaviour is not evident in the 1920 $\mathrm{nm}$ diagram until the evaporation regime of less than 0.1 . The behaviour can be explained by the presence of more bitumen in sample MFT3. Since both the $1920 \mathrm{~nm}$ and $2205 \mathrm{~nm}$ reflectance values showed a nonlinear trend with respect to the $\mathrm{AE} / \mathrm{PE}$, second-order polynomials were employed for model development. This nonlinear behaviour (also observed in sections below) is presumably associated with the nonlinear relationship between $\mathrm{AE} / \mathrm{PE}$ and total suction (Fig. 1(b)). $\mathrm{R}^{2}$ of 0.97 and 0.95 were obtained for the absolute reflectance at $1920 \mathrm{~nm}$ and $2205 \mathrm{~nm}$, respectively. $\mathrm{R}^{2}$ values of greater than 0.9 indicate that absolute reflectance can be considered to be capable of measuring normalized evaporation from oil sands tailings. Atmospheric effect is, however, an obstacle for the use of $1920 \mathrm{~nm}$ reflectance under the field conditions.

\section{Absorption depth}

The changes in band depths at $1450 \mathrm{~nm}$ and $1925 \mathrm{~nm}$ with changes in AE/PE are shown in Figs. 5(d) and 5(e), respectively. In both cases, the depth decreases with decreasing 
evaporation. For the absorption depth at $1450 \mathrm{~nm}$, the sensitivity of the feature is lost below an $\mathrm{AE} / \mathrm{PE}$ value of 0.4 , a behavior that is not observed for the absorption depth at $1925 \mathrm{~nm}$. As can be seen in Figs. 5(d) and 5(e), these absorption depths are not sensitive to the composition of tailings. Moreover, the absorption depths appear not to be affected by bitumen concentration as the sample with more bitumen content (MFT3) does not show a distinct behaviour. Second-order polynomials were used to model the variations of evaporation with variation of absorption depths at $1450 \mathrm{~nm}$ and $1925 \mathrm{~nm}$. $\mathrm{R}^{2}$ values of 0.94 and 0.96 were calculated for the $1450 \mathrm{~nm}$ and $1925 \mathrm{~nm}$ absorption depths, respectively. Although these spectral features are successful in prediction of evaporation from the tailings surface under the laboratory conditions, they are not applicable on the spectral data collected in the field due to the effect of the atmosphere on these absorption bands.

NSMI

The values of NSMI were calculated and plotted for all the samples examined. Fig. 5(f) shows the relationship between the NSMI and normalized evaporation. Between AE/PE evaporation rates of 0.2 to 0.8 , this index seems to be insensitive to the tailings composition. However, above 0.8 and below 0.2 evaporation rate, the index starts to show some variations. In particular, when the rate of evaporation is very low (below 0.1), NSMI appears to be sensitive to the samples composition including the bitumen concentration. An $\mathrm{R}^{2}$ value of 0.95 was achieved by fitting a second-order polynomial to the data. As the NSMI is not affected by the atmospheric conditions, it can be a good estimator of normalized evaporation (AE/PE) when using the field data. 


\section{Discussion}

\section{Field applications}

The predictive models developed in this study are intended to apply to hyperspectral data acquired in field settings by imaging the MFT tailings and sensing the top few hundred microns of the surface. Thus, the spectral sensing is able to estimate moisture content and AE/PE from the very top surface of the tailings. This is valuable information for tailings management and could help to assess when the deposit has stopped drying at the surface as part of a decision process to determine when the next lift should be deposited. In addition, the moisture content and normalized evaporation at the surface can contribute to the estimation of the water profile under the surface using empirical models, a topic of future research.

\section{Estimation of total suction at the tailings surface}

The results of this study demonstrate the capability of remote hyperspectral technology for the estimation of normalized evaporation. Since there exists a relationship between the normalized evaporation and the total suction (i.e. matric suction plus osmotic suction) as described by Wilson et al (1997) that is independent of water content and soil composition, one can estimate the total suction for the top few hundreds of microns of the surface by measuring the normalized evaporation from hyperspectral observations. According to Eq. (2), to measure the total suction, it is required to measure the normalized evaporation, surface temperature of the soil, and relative humidity of the air. The normalized evaporation can be estimated using the hyperspectral data as presented in this study. Long Wave InfraRed (LWIR) hyperspectral data, on the other hand, can be used to estimate the surface temperature of the soil in field applications. Therefore, by employing the SWIR and LWIR hyperspectral technology, measuring the total suction of the surface in field applications is feasible. It should be noted that the established relationship between normalized evaporation 
and total suction was demonstrated for thin soil sections as described by Wilson et al. (1997). Nevertheless, special care and attention must be used when applying the relationship to soil columns or for field applications since spatial variation, both vertically and horizontally, in water content and total suction occur. In other words, uniform drying in natural systems should not be expected.

\section{Effect of specular reflection}

The behaviour of the $1985 \mathrm{~nm}$ and $2205 \mathrm{~nm}$ reflectance with varying water content in the high moisture regime (approximately above $20 \mathrm{wt} \%$ moisture content) appeared to be counterintuitive. As can be seen in Figs. 4(b) and 4(c) the initial decrease in water content results in an increase in reflectance as expected. But a peak in reflectance is then observed nominally around $40 \mathrm{wt} \%$ moisture content where reflectance is higher than expected (a hump in the curves). The expected pattern in reflectance resumes at lower moisture content (e.g. 20-30 wt\%). Our investigations revealed that this unexpected behaviour is attributable to the contribution of specular (e.g. mirror like) reflections from the water surface in domains of the sample undergoing the onset surface exposure from the water film. It is an ephemeral phenomenon that disappears as the sample dries. This phenomenon was documented using a series of photos (Fig. 6) taken at a normal view to the MFT sample (the same position as the sensor) during a dehydration experiment. As can be seen in these photos, the sample surface is initially covered by a continuous water film that progressively thins. The photo at 50.4 $\mathrm{wt} \%$ water content displays the first evidence of specular reflection (areas with very high reflection) in the left part of the sample. The presence of these reflections are attributed to the formation of surface microtopography as drying occurs that provided localized mirror like bright returns. Their extent increases in subsequent photos for lower moisture content but they clearly have begun to wane for the photo at $39.1 \mathrm{wt} \%$ moisture content as standing water 
has largely disappeared. This phenomenon is the cause for the observed increase in the absolute reflectance at $1985 \mathrm{~nm}$ and $2205 \mathrm{~nm}$, as the water content decreases to approximately 20-30 wt $\%$ moisture regime.

\section{Effect of non-uniform drying pattern}

It was observed during the experiments that non-uniform drying pattern of the samples introduces variability in spectral measurements. The non-uniform drying pattern on the sample surface is mainly attributed to non-uniform sample thickness and illumination. Although the footprint of the spectrometer was adjusted to cover the whole sample area, it was observed that the central part in the field of view contributes more to the final spectra collected than the edge. As a result, for instance, a sample at certain moisture content with wet central part shows a lower reflectance and deeper water absorption band than a sample at the same moisture content with dry central part. Fig. 7 shows all the samples examined in the evaporation tests at $20 \mathrm{wt} \%$ moisture content. The central part of MFT samples $2 \& 4$ is wetter than the central part of MFT samples $1 \& 3$, resulting in a lower reflectance and deeper water absorption depth at $20 \mathrm{wt} \%$ moisture content. This explains the offset between the behaviour of the MFT samples $1 \& 3$ and MFT samples $2 \& 4$ in Fig. 4.

\section{Stability assessment of the spectrometer}

A test performed in the laboratory to assess the stability of the ASD instrument showed that by warming up the instrument for about 2 hours, the instrument would be stable enough and there is therefore no need to measure the white panel frequently during the experiment. Thus, normalization of each measurement to that of a standard white reference panel for calculation of reflectance was only conducted at the beginning of each experiment. It should be noted that measuring the white panel during the experiment could introduce 
errors in measuring the actual evaporation rate as the tailing container needed to be replaced by the panel in order to measure the white reference panel spectrum. This disturbance could cause fluctuations in the rate of evaporation.

\section{Conclusions}

This paper investigated the use of SWIR hyperspectral remote sensing data for estimating the moisture content and normalized evaporation of oil sands soft tailings surfaces. Measurements of the moisture content and the exchange of water between the soil surface and the atmosphere are of importance for many geotechnical problems. In the case of tailings management, the remote estimation of moisture content and evaporation helps to assess the drying process, to determine when the deposit has stopped drying and to decide when the next lift should be deposited.

All SWIR spectral features examined were of value for the estimation of water content and normalized evaporation of the MFTs. For the estimation of moisture content, the best result was achieved using the NSMI index $\left(\mathrm{R}^{2}=0.97\right)$. The absolute reflectance at 1920 $\mathrm{nm}$ was found to be the best spectral estimator of normalized evaporation $\left(\mathrm{R}^{2}=0.97\right)$ with the NSMI index also being of value $\left(\mathrm{R}^{2}=0.95\right)$. However, NSMI appears to be sensitive to the sample composition including the bitumen concentration when the evaporation rate is very low. In both instances the NSMI index may be of value for estimations in the field while the reflectance at $1920 \mathrm{~nm}$ may not due to its sensitivity to atmospheric conditions.

The samples examined in this study were obtained from a single mine and were processed using the same tailings operation technology. Future work could incorporate samples from different mines and tailings process to assess the robustness of our findings to tailings composition. The long term goal is to develop a new tool to monitor moisture content and evaporation over a wide range of tailings and generate real-time maps of tailings 
properties. In future efforts, the models obtained from this laboratory investigation will be assessed for their applicability in field settings and validated using concurrent sampling. Developing such a remote mapping capability offers a key enabling technology to assess key characteristics of tailing deposits as a supplement to standard geotechnical testing and sampling campaigns.

\section{Acknowledgments}

The authors would like to acknowledge the Institute for Oil Sands Innovation (IOSI) at the University of Alberta, the Canada's Oil Sands Innovation Alliance (COSIA), and Shell Canada for their support of this research.

\section{References}

Alberta Energy. 2014. Alberta's Oil Sands: The Facts. Government of Alberta, Edmonton, Alberta, Canada.

Barton, I.J. 1979. A parameterization of the evaporation from non-saturated surfaces. Journal of Applied Meteorology, 18: 43-47.

BGC Engineering Inc. 2010. Oil Sands Tailings Technology Review. Oil Sands Research and Information Network, University of Alberta, School of Energy and the Environment, Edmonton, Alberta. OSRIN Report No. TR-1. 136 pp.

Boratynec, D.J., Chalaturnyk, R.J. and Scott, J.D. 1998. Experimental and fundamental factors affecting the water release rates of CT. In Proceedings of the $51^{\text {st }}$ Canadian Geotechnical Conference, Edmonton, Alberta, Canada, 4-7 October 1998, pp. 607-614.

Brutsaert, W.H. 1982. Evaporation into the atmosphere: theory, history and applications. P. Reidel Publishing Company, Dordrecht, The Netherlands.

COSIA/OSTC. 2012. Technical guide for fluid fine tailings management. 
Da Silva, F., Graham, M., Scott, J.D., and Wilson, G.W. 2014. Evaluation of a new treatment technology for improving oil sands tailings management. In Proceedings of GeoRegina 2014, Regina, Saskatchewan, Canada, September 28 - October 1, 2014.

FTFC (Fine Tailings Fundamentals Consortium). 1995. Advances in oil sands tailings research. Alberta Department of Energy, Oil Sands and Research Division, Edmonton, Canada.

Granger, R.J. 1989a. An examination of the concept of potential evaporation. Journal of Hydrology. 111: 9-19.

Granger, R.J. 1989b. Evaporation from natural non-saturated surfaces. Journal of Hydrology. 111: 21-29.

Gray, D.M. 1970. Handbook on the principals of hydrology. Canadian National Committee for the International Hydrological Decade, National Research Council of Canada, Ottawa, Canada.

Hammel, J.E., Papendick, R.I., and Campbell, G.S. 1981. Fallow tillage effects on evaporation and seedzone water content in a dry summer climate. Soil Science Society of America Journal. 45: 1016-1022.

Haubrock, S.N., Chabrillat, S., Lemmintz, C., and Kaufmann, H. 2008. Surface soil moisture quantification models from reflectance data under field condition. International Journal of Remote Sensing. 29(1): 3-39.

Hillel, D. 1980. Applications of soil physics. Academic Press, New York.

Holmes, R.M. 1961. Estimation of soil moisture content using evaporation data. In Proceedings of Hydrology Symposium, No. 2 Evaporation. Queen's Printer, Ottawa, pp. $184-196$.

Kasperski, K.L. 1992. A review of properties and treatment of oil sands tailings. AOSTRA Journal of Research, 8: 11-15. 
Lipsett, M.G., Olmedo, N., Rivard, B., and Wilson, W. 2014. Robotic systems for measuring properties of tailings deposits and collecting samples. In Proceedings of Fourth International Oil Sands Tailings Conference (IOSTC 2014), Lake Louise, AB, Canada, 7-10 December 2014, pp. 483-491.

MacKinnon, M.D. 1989. Development of the tailings pond at Syncrude's oil sands plant: 1978-1987. AOSTRA Journal of Research, 5: 109-33.

Mikula, R.J., Munoz, V.A., and Omotoso, O. 2009. Centrifugation options for production of dry stackable tailings in surface mined oil sands tailings management. Journal of Canadian Petroleum Technology. 48(9): 19-23.

Morton, F.I. 1975. Estimating evaporation and transpiration from climatological observations. Journal of Applied Meteorology. 14(4): 488-497.

Morton, F.I. 1985. The complementary relationship areal evapotranspiration model: How it works. In Proceedings of the National Conference on Advances in Evapotranspiration, American Society of Agricultural Engineers, Chicago, Illinois, pp. 377-384.

National Energy Board. 2004. Canada's Oil Sands: opportunities and challenges to 2015 [Pamphlet], Calgary, AB.

Penman, H.L. 1948. Natural evapotranspiration from open water, bare soil and grass. In Proceedings of the Royal Society of London, Series A, 193: 120-145.

Scott, J.D., Jeeravipoolvarn, S., Donahue, R. and Ozum, B. 2008. Characterization of oil sands thickened tailings. In Proceedings of First International Oil Sands Tailings Conference, Edmonton, Alberta, Canada, 7-10 December 2008, pp. 132-142.

Thornthwaite, C.W. 1948. An approach toward a rational classification of climate. Geographical Review. 38: 55-94.

Wilson, G.W., Fredlund, D.G., and Barbour, S.L. 1994. Coupled soil-atmosphere modeling for soil evaporation. Canadian Geotechnical Journal. 31: 151-161.

Wilson, G.W., Fredlund, D.G., and Barbour, S.L. 1997. The effect of soil suction on evaporative fluxes from soil surface. Canadian Geotechnical Journal. 34: 145-155. 
Yanful, E.K., Bell, A.V., and Woyshner, M.R. 1993. Design of a composite soil cover for an experimental waste rock pile near Newcastle, New Brunswick, Canada. Canadian Geotechnical Journal. 30: 578-587. 


\section{List of Figures}

Fig. 1. (a) Relationship between normalized evaporation (AE/PE) and water availability (after Holmes 1961). (b) Relationship between normalized evaporation (AE/PE) and suction (Wilson et al. 1997).

Fig. 2. (a) Photographs of air-dried samples (b) Experimental setup. Left petri dish contains MFT and right one contains water. (c) Reflectance spectra of dry and wet MFT1.

Fig. 3. Water content and evaporation results: (a) Water content versus time. (b) Normalized evaporation ( $\mathrm{AE} / \mathrm{PE}$ ) versus time. (c) Corrected normalized evaporation ( $\mathrm{AE} / \mathrm{PE})$ versus time. (d) Normalized evaporation (AE/PE) versus water content.

Fig. 4. Reflectance spectroscopy results: (a) Correlation coefficient between reflectance and water content as a function of wavelength. (b) Reflectance at $1985 \mathrm{~nm}$ versus water content. (c) Reflectance at $2205 \mathrm{~nm}$ versus water content. (d) Absorption depth at $1450 \mathrm{~nm}$ versus water content. (e) Absorption depth at $1925 \mathrm{~nm}$ versus water content. (f) NSMI versus water content.

Fig. 5. Relationship of spectral metrics to AE/PE: (a) for correlation coefficient of reflectance as a function of wavelength. (b) for reflectance at $1920 \mathrm{~nm}$. (c) for reflectance at $2205 \mathrm{~nm}$. (d) for absorption depth at $1450 \mathrm{~nm}$. (e) for absorption depth at $1450 \mathrm{~nm}$. (f) for NSMI.

Fig. 6. Photographs of the MFT sample during a dehydration experiment showing formation and disappearance of the specular reflection.

Fig. 7. Photographs of samples at $20 \mathrm{wt} \%$ moisture content. 

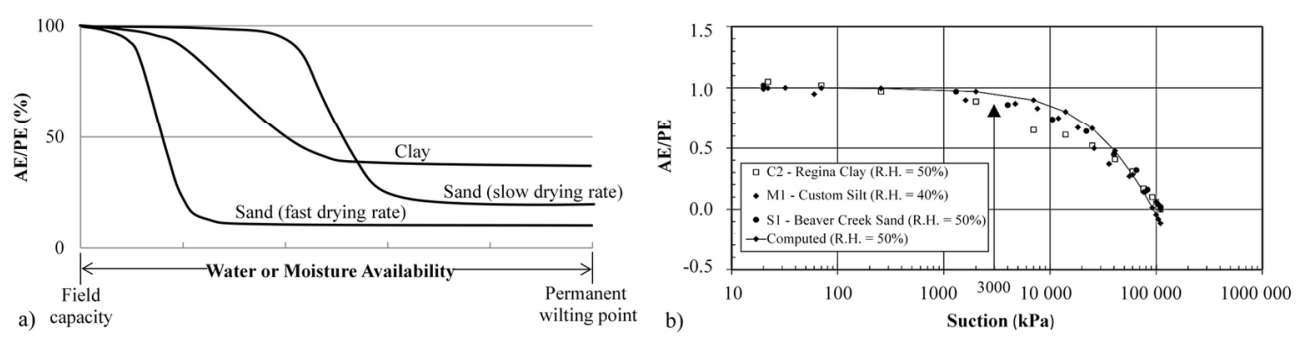

Fig. 1. (a) Relationship between normalized evaporation (AE/PE) and water availability (after Holmes 1961). (b) Relationship between normalized evaporation (AE/PE) and suction (Wilson et al. 1997).

$73 \times 18 \mathrm{~mm}(600 \times 600 \mathrm{DPI})$ 


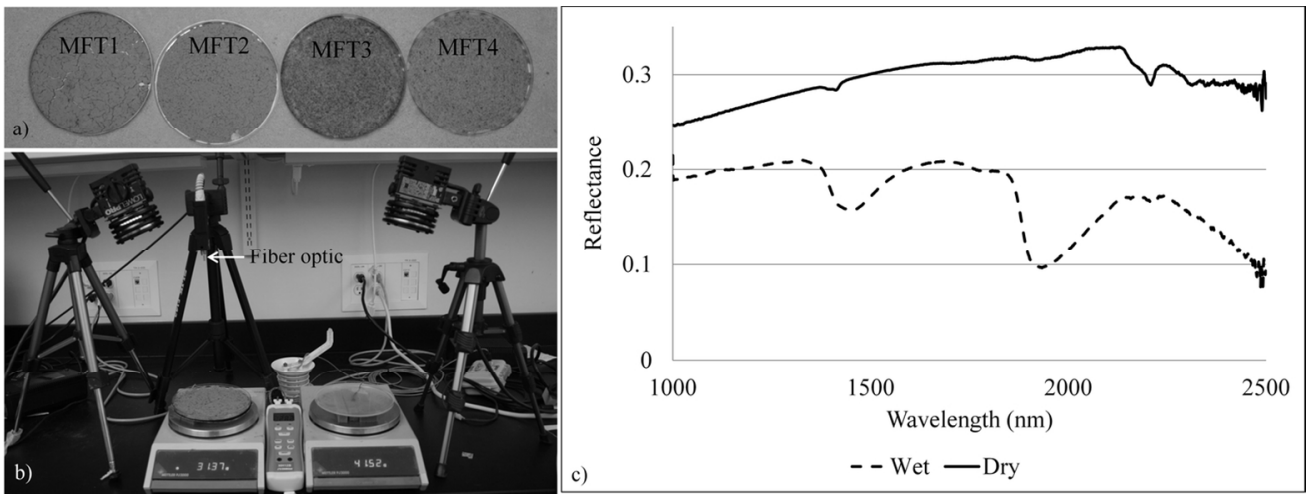

Fig. 2. (a) Photographs of air-dried samples (b) Experimental setup. Left petri dish contains MFT and right one contains water. (c) Reflectance spectra of dry and wet MFT1.

$$
128 \times 48 \mathrm{~mm}(300 \times 300 \text { DPI })
$$




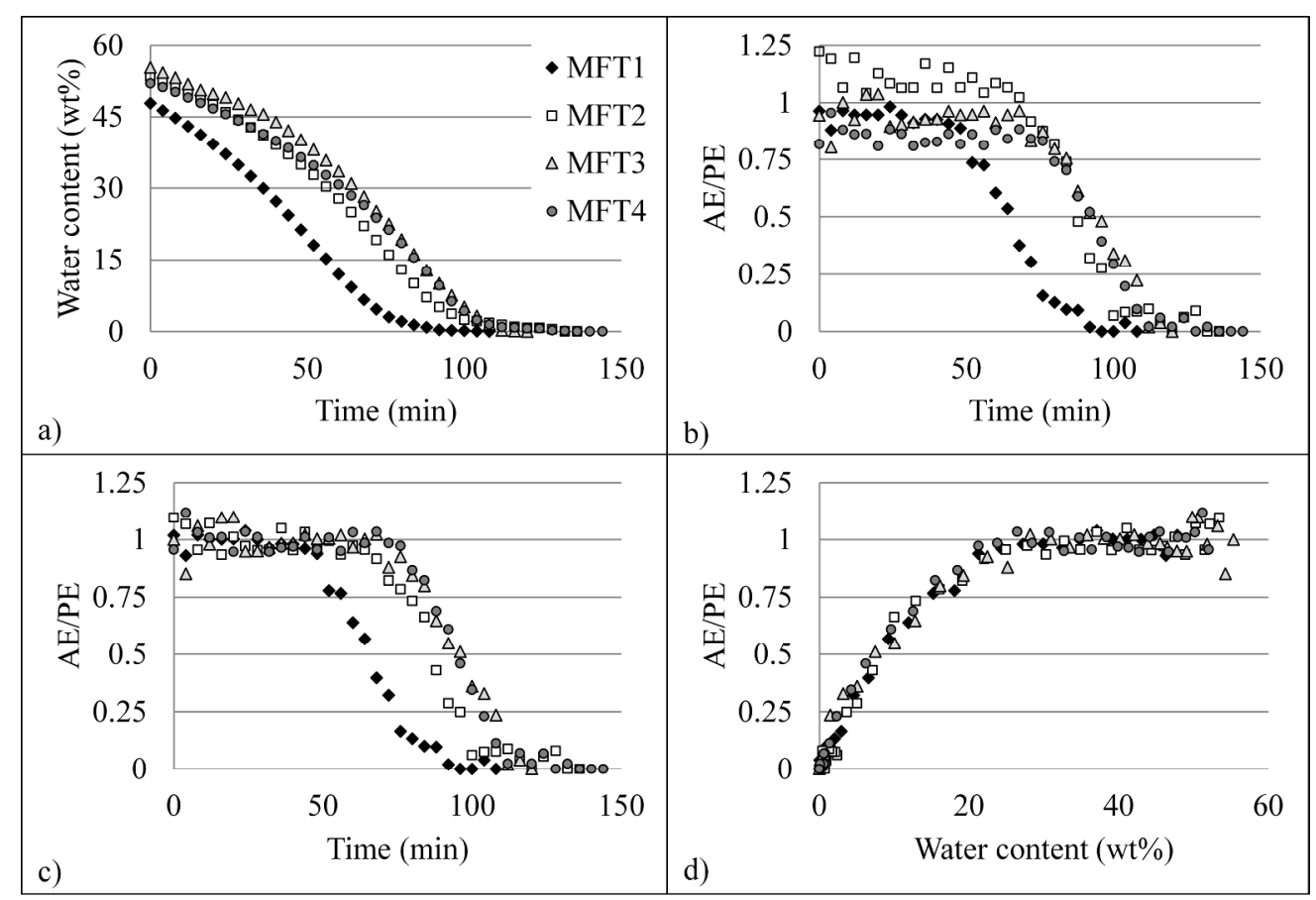

Fig. 3. Water content and evaporation results: (a) Water content versus time. (b) Normalized evaporation $(A E / P E)$ versus time. (c) Corrected normalized evaporation (AE/PE) versus time. (d) Normalized evaporation $(A E / P E)$ versus water content.

$$
137 \times 93 \mathrm{~mm}(600 \times 600 \mathrm{DPI})
$$




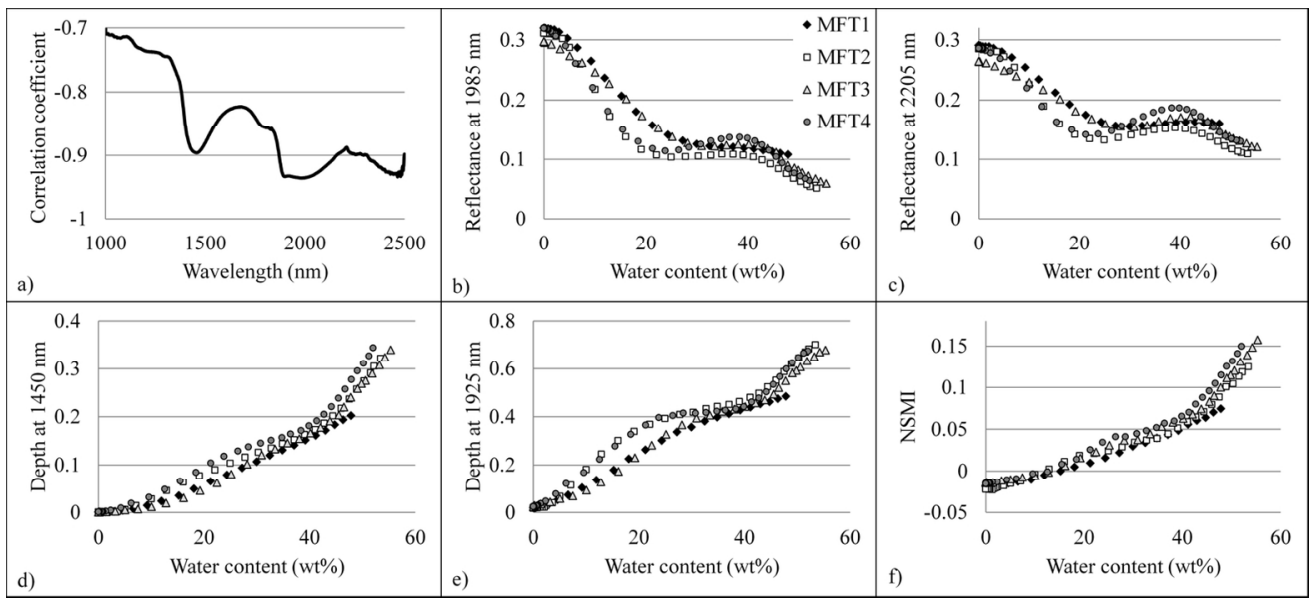

Fig. 4. Reflectance spectroscopy results: (a) Correlation coefficient between reflectance and water content as a function of wavelength. (b) Reflectance at $1985 \mathrm{~nm}$ versus water content. (c) Reflectance at $2205 \mathrm{~nm}$ versus water content. (d) Absorption depth at $1450 \mathrm{~nm}$ versus water content. (e) Absorption depth at 1925 $\mathrm{nm}$ versus water content. (f) NSMI versus water content.

$$
137 \times 62 \mathrm{~mm}(300 \times 300 \mathrm{DPI})
$$




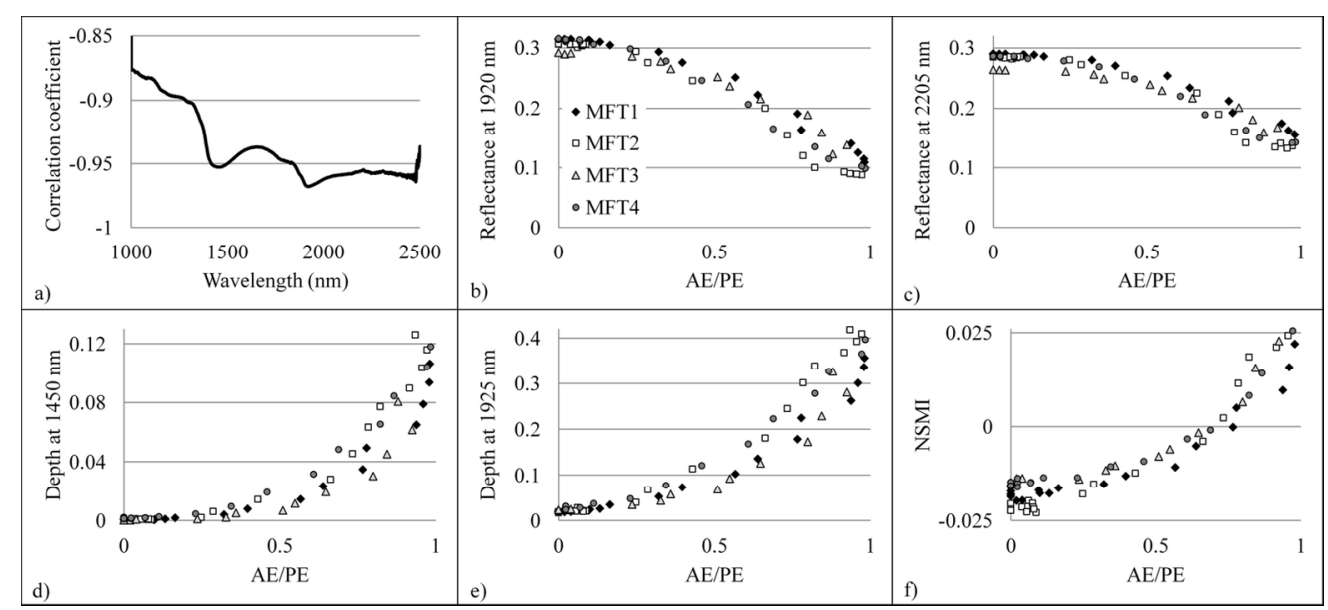

Fig. 5. Relationship of spectral metrics to AE/PE: (a) for correlation coefficient of reflectance as a function of wavelength. (b) for reflectance at $1920 \mathrm{~nm}$. (c) for reflectance at $2205 \mathrm{~nm}$. (d) for absorption depth at 1450 $\mathrm{nm}$. (e) for absorption depth at $1450 \mathrm{~nm}$. (f) for NSMI.

$137 \times 62 \mathrm{~mm}(300 \times 300 \mathrm{DPI})$ 

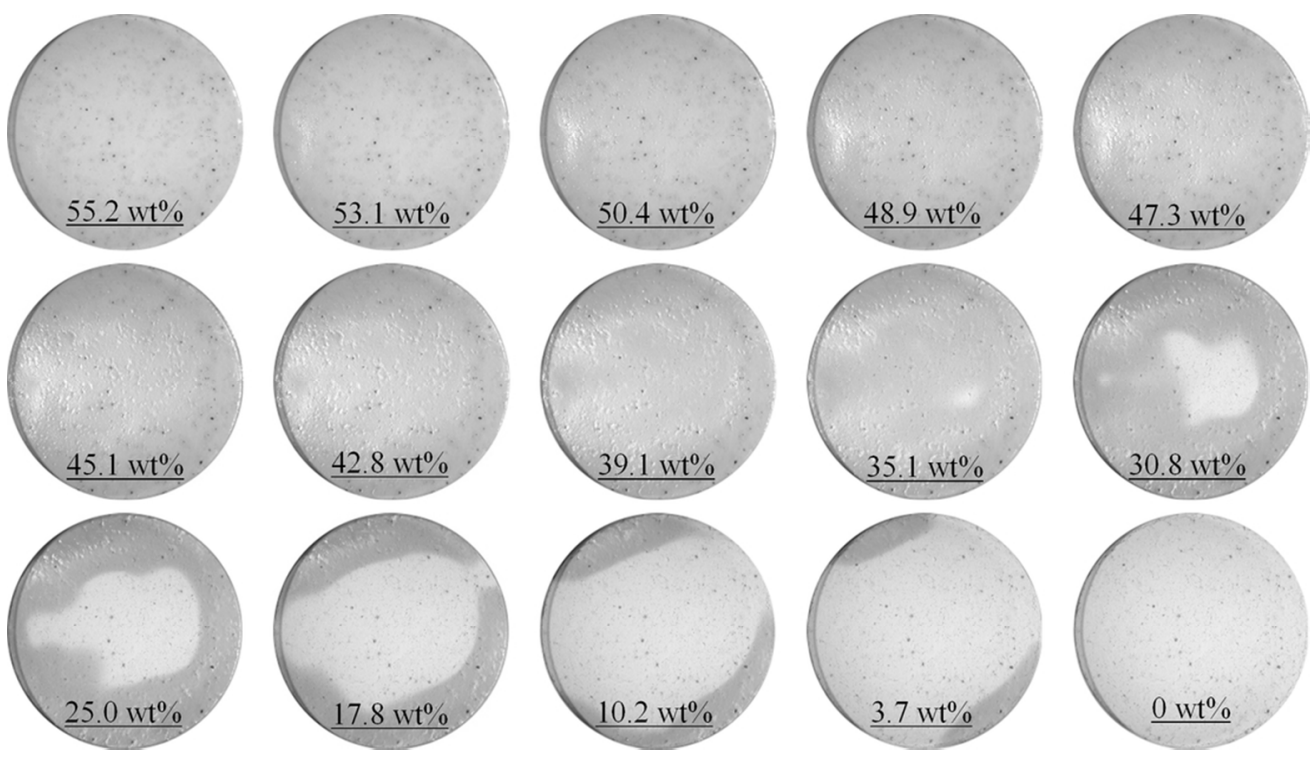

Fig. 6. Photographs of the MFT sample during a dehydration experiment showing formation and disappearance of the specular reflection.

$93 \times 52 \mathrm{~mm}(300 \times 300 \mathrm{DPI})$ 


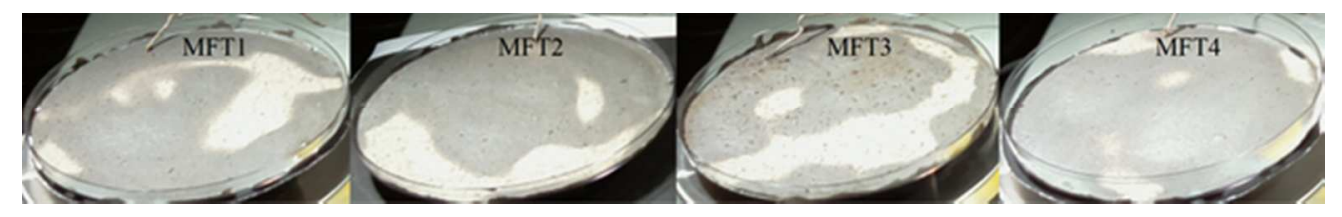

Fig. 7. Photographs of samples at $20 \mathrm{wt} \%$ moisture content.

$26 \times 3 \mathrm{~mm}(600 \times 600 \mathrm{DPI})$ 
Table 1. Characteristics of MFT samples examined.

\begin{tabular}{ccccccc}
\hline Sample & Solids & Bitumen & MBI & \multicolumn{3}{c}{ PSD (wt\%) } \\
\cline { 5 - 7 } No. & $\mathbf{( w t \% )}$ & $\mathbf{( w t \% )}$ & $(\mathbf{m e q} / \mathbf{1 0 0 g})$ & $<\mathbf{2 \mu m}$ & $<\mathbf{4 4} \boldsymbol{\mu m}$ & $<\mathbf{7 4} \boldsymbol{\mu m}$ \\
\hline MFT1 & 52.16 & 3.5 & 2.3 & 8.90 & 70.83 & 83.23 \\
MFT2 & 46.55 & 4.0 & 2.3 & 9.97 & 71.65 & 83.53 \\
MFT3 & 44.66 & 4.3 & 3.5 & 10.71 & 82.78 & 91.53 \\
MFT4 & 47.96 & 3.3 & 3.4 & 8.39 & 72.09 & 83.59 \\
\hline
\end{tabular}


Table 2. Summary of key evaporation test parameters.

\begin{tabular}{ccccc}
\hline $\begin{array}{c}\text { Sample } \\
\text { No. }\end{array}$ & $\begin{array}{c}\text { Initial water } \\
\text { content }(\mathbf{w t} \%)\end{array}$ & $\begin{array}{c}\text { Test duration } \\
(\mathbf{m i n})\end{array}$ & $\begin{array}{c}\text { Mean room air } \\
\text { temperature }\left({ }^{\mathbf{}} \mathbf{C}\right)\end{array}$ & $\begin{array}{c}\text { Mean relative } \\
\text { humidity of air }(\mathbf{\%})\end{array}$ \\
\hline MFT1 & 47.84 & 108 & 23.25 & 22.5 \\
MFT2 & 53.45 & 136 & 24.10 & 21.4 \\
MFT3 & 55.34 & 120 & 24.30 & 21.9 \\
MFT4 & 52.04 & 140 & 23.20 & 35.3 \\
\hline
\end{tabular}

